\title{
Adoptive cellular therapy enhances the helper $T$ cell response and reduces the number of regulatory $T$ cells
}

\author{
TAKESHI ISHIKAWA ${ }^{1}$, SATOSHI KOKURA ${ }^{1}$, NAOYUKI SAKAMOTO ${ }^{2}$, TSUGUHIRO MATSUMOTO ${ }^{1}$, \\ JUN FUNAKI $^{1}$, SATOKO ADACHI $^{1}$, TETSUYA OKAYAMA ${ }^{1}$, KAZUHIKO UCHIYAMA ${ }^{1}$, \\ OSAMU HANDA ${ }^{1}$, TOMOHISA TAKAGI ${ }^{1}$, NOBUAKI YAGI ${ }^{1}$, TAKASHI ANDO ${ }^{1}$, \\ KAZUKO UNO $^{3}$, YUJI NAITO ${ }^{1}$ and TOSHIKAZU YOSHIKAWA ${ }^{1}$ \\ ${ }^{1}$ Department of Molecular Gastroenterology and Hepatology, Graduate School of Medical Science, \\ Kyoto Prefectural University of Medicine; ${ }^{2}$ Iseikai Hyakumanben Clinic; \\ ${ }^{3}$ Louis Pasteur Center for Medical Research, Kyoto, Japan
}

Received January 18, 2011; Accepted April 15, 2011

DOI: 10.3892/etm.2011.271

\begin{abstract}
It remains to be clarified whether adoptive cellular therapy (ACT) in patients with advanced cancer, in whom strong immunosuppression and immune-escape mechanisms are established, has the potential to alter cytokine secretion from blood cells and affect the number of regulatory $\mathrm{T}$ cells (Tregs). In this study, the secretion of cytokines from peripheral blood cells and the number of peripheral blood Tregs were analyzed before and after ACT. Blood samples were collected from 109 consecutive cancer patients who received ACT, which consisted of anti-CD3 stimulated lymphokineactivated killer cells. For testing immune function, venous blood was obtained from patients before the start of therapy and after they had received 4 cycles of ACT. Of the 109 patients, 76 received ACT four times or more. All 109 blood samples at baseline and 76 follow-up samples were available. The secretion ability of various cytokines from peripheral blood cells was measured, as well as the number of peripheral blood Tregs. We found that the secretion ability of interferon (IFN) $-\gamma$ and tumor necrosis factor (TNF)- $\alpha$ was enhanced significantly after treatment, while the number of Tregs and the ratio of Treg to CD4 was significantly decreased. Overall
\end{abstract}

Correspondence to: Professor Satoshi Kokura, Department of Molecular Gastroenterology and Hepatology, Graduate School of Medical Science, Kyoto Prefectural University of Medicine, Kyoto 603-8151, Japan

E-mail: s-kokura@koto.kpu-m.ac.jp

Abbreviations: ACT, adoptive cellular therapy; CTLs, cytotoxic $\mathrm{T}$ cells; TGF, transforming growth factor; IL, interleukin; TNF- $\alpha$, tumor necrosis factor- $\alpha$; IFN, interferon; Tregs, regulatory T cells; Th, CD4 ${ }^{+} \mathrm{T}$ helper; CD3-LAK, anti-CD3 stimulated lymphokineactivated killer; PHA, phytohemagglutinin; ECOG, Eastern Cooperative Oncology Group

Key words: adoptive cellular therapy, cytokine, regulatory $\mathrm{T}$ cell, cancer survival in patients with increased IFN- $\gamma$ and TNF- $\alpha$ secretion after ACT was significantly longer. These findings suggest a potential therapeutic role for ACT in cancer immunotherapy.

\section{Introduction}

Cancer-directed immune-based therapies focus on eliciting a cytotoxic T cell (CTL) response due to the fact that CTLs directly kill tumor cells. However, most of these strategies have been occluded by strong immunosuppression and immune-escape mechanisms that become established in tumor-bearing hosts $(1,2)$. Tumor-induced immune suppression is caused by numerous mechanisms, many of which involve the accumulation of immune-suppressive infiltrates into the tumor microenvironment. One of the most potent and well-studied suppressive phenotypes found in the tumor microenvironment is the regulatory $\mathrm{T}$ cell (Treg). Tumors may differentiate, expand, recruit and activate Tregs via multiple mechanisms, and potentially abrogate antitumor immunity (3). Tregs have been shown to increase in the tumor and the peripheral blood of patients with cancer (4-12), and to be inversely related to the outcome of several types of human malignancies $(10,12)$. Consistent with these findings, previous studies have demonstrated that deletion of Tregs results in the enhancement of effective tumor immune responses via the removal of such strong immunosuppression (13-18). Therefore, blocking the migration of Tregs or their function by means of immunotherapeutic approaches may prove beneficial in cancer therapy.

Recently, it has been reported that $\mathrm{CD}^{+} \mathrm{T}$ helper (Th) cells are crucial for the induction of effective antitumor immunity. Th cells are primarily responsible for enhancing and sustaining $\mathrm{CD}^{+} \mathrm{T}$ cell responses $(19,20)$. Apart from the key role of $\mathrm{CD}^{+}$cells in controlling $\mathrm{CD}^{+} \mathrm{T}$ cell reactivity to antigens, which emphasizes the distinct roles of Th1 and Th2 cells in tumor eradication, it has been demonstrated that $\mathrm{Th}$ cells have direct cytolytic effects via multiple pathways $(21,22)$ and activate antigen-presenting cells (23). In addition, Zhang et al demonstrated in an animal model that Th1 cell therapy 
significantly inhibits the accumulation of Tregs in tumordraining lymph nodes and that this abrogation is associated with interferon (IFN)- $\gamma$ secreted from Th1 cells (24). By introducing Th1-dominant immunity and reducing the number of Tregs, overcoming immunosuppression and inducing fully activated tumor-specific CTLs becomes critically important. Several potential mechanisms by which Th cell therapy modulates the tumor microenvironment include enhancing the production of inflammatory cytokines and reducing the number of Tregs, thus supporting the elaborate tumor-specific immune response. Despite this encouraging data, clinical use of Th cells remains limited because of technical difficulties in acquiring and expanding Th cells to the numbers deemed necessary for adoptive cellular therapy (ACT) to be effective (25).

Anti-CD3 stimulated lymphokine-activated killer (CD3-LAK) cells used in this study have been reported to be effective in therapeutic animal models $(26,27)$, whereby CD3-LAK cells are already being used in clinical applications. Although CD3-LAK therapy was found to be only minimally effective in the treatment of large tumor burdens, adjuvant use of CD3-LAK therapy is reported to contribute to significant risk reduction of tumor recurrence $(28,29)$. There are many reports that CD3-LAK cells display non-specific lytic activity in a broad spectrum of tumors (30). However, it remains to be clarified whether CD3-LAK therapy in patients with advanced cancer, in whom strong immunosuppression and immune-escape mechanisms are established, has the potential to alter cytokine secretion from blood cells and affect the number of Tregs. To resolve these issues, the secretion ability of cytokines in whole blood and the number of peripheral blood Tregs before and after ACT using CD3-LAK cells were examined in advanced cancer patients. The relationship of the immunological response with clinical efficacy after ACT treatment was also assessed.

\section{Patients and methods}

Patients and blood samples. Blood samples from 109 consecutive cancer patients who were scheduled to receive ACT with CD3-LAK cells were collected intravenously at Hyakumanben Clinic between October 2008 and December 2009. Among the 109 patients, 3 received ACT as postoperative adjuvant therapy for the prevention of disease recurrence, and 106 received this therapy for advanced or recurring diseases. The patients received ACT at 2-week intervals and this continued until they were unable to receive further treatment due to either poor general condition or if they refused any further treatment. For testing immune function, venous blood was obtained from patients before starting the therapy and during the follow-up, which was after 4 cycles of ACT. Of the 109 patients, 76 received ACT four times or more. First follow-up blood sampling was carried out immediately before the 5th ACT ( 2 weeks after the 4th ACT; Fig. 1). All 109 blood samples at baseline and 76 first follow-up samples were available.

Healthy individuals were selected as controls for comparison with our cancer patients. Of the 49 healthy subjects, 41 were men and 8 were women. These subjects were selected from individuals receiving medical examinations at the clinic

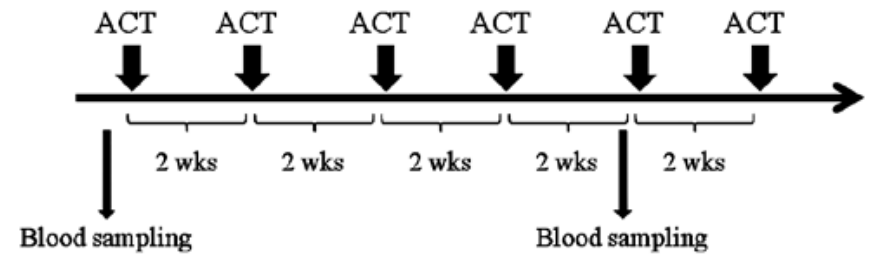

Figure 1. Clinical protocol.

who had no acute or chronic disease. The median age of the healthy controls was 54 years (range 40-78).

All subjects gave written informed consent. The institutional review board approved the present study.

Lymphokine-activated killer cell preparation. Peripheral blood (30-40 ml) was taken from the patients. Mononuclear cells were separated and resuspended in a CultiLife215 bag (Takara Bio, Otsu, Japan) pre-coated with anti-CD3 (Janssen Pharmaceutical, Tokyo, Japan) and then cultured in serumfree media, GT-T505 (Takara Bio), supplemented with $1 \%$ heat-inactivated plasma and $1,000 \mathrm{U} / \mathrm{ml}$ recombinant interleukin (IL)-2 (Nipro, Osaka, Japan) for 2 days. At day 7, the cells were transferred to a CultiLifeEva bag (Takara Bio), and GT-T503 media was added. At day 9, IL-2 and 1\% heat-inactivated plasma were added. At day 14, the cells were harvested and resuspended in $100 \mathrm{ml}$ saline with $1 \%$ human albumin, as the final cell product. These cell products were assessed for viability and checked for contamination with bacteria, fungi and endotoxins.

Cytokine assay. Methods for quantifying IFN- $\gamma$ production in whole human blood have been described previously (31). Briefly, heparinized peripheral blood was cultured with Sendai virus (HVJ, $500 \mathrm{HA} / \mathrm{ml})$ within $8 \mathrm{~h}$ after the withdrawal of blood. The blood-virus mixture was incubated at $37^{\circ} \mathrm{C}$ for $20 \mathrm{~h}$, and IFN- $\gamma$ activity in the supernatants was quantified by bioassay. Other cytokines were measured according to the following procedure: heparinized whole blood was diluted 4-fold with Eagle's minimal essential medium (MEM; Nissui Pharmaceutical Co., Ltd., Tokyo, Japan) and stimulated with phytohemagglutinin (PHA; $25 \mu \mathrm{g} / \mathrm{ml}$ ). After $48 \mathrm{~h}$ of incubation at $37^{\circ} \mathrm{C}$, supernatants were harvested by centrifugation at $800 \mathrm{x} \mathrm{g}$ for $10 \mathrm{~min}$ and stored at $-80^{\circ} \mathrm{C}$ until analysis. Cytokine levels in the samples were measured using a multiplex cytokine array system (Bio-Plex; Bio-Rad Laboratories, Hercules, CA, USA) according to the manufacturer's instructions. The Multiplex Th1/Th2 bead kit (Bio-Rad) included various cytokines [IL-2, IL-4, IL-5, IL-10, IL-12(p70), IL-13, TNF- $\alpha$, IFN- $\gamma$ and granulocyte-monocyte colony-stimulating factor (GM-CSF)]. Data acquisition and analysis were carried out using the Bio-Plex Manager Software, version 5.0.

Flow cytometric analysis. To determine the regulatory cell phenotype, flow cytometry of whole blood was performed using the following antibodies: $\mathrm{PE}-\mathrm{Cy}^{\mathrm{TM}} 5$ mouse anti-human CD4; PE mouse anti-human CD25, Alexa Fluor ${ }^{\circledR} 488$ mouse anti-human Foxp3 and Alexa Fluor ${ }^{\circledR} 488$ mouse IgG1 $\kappa$ isotype control (all purchased from BD Biosciences Pharmingen, San Diego, CA, USA). For whole blood staining, $500 \mu \mathrm{l}$ of whole 
blood was incubated with appropriate amounts of fluorochrome-labeled antibodies in the dark at room temperature for 30 min. After lysing red blood cells using BD FACS ${ }^{\text {тм }}$ lysing solution, cells were treated with human FoxP3 buffer A and buffer $\mathrm{B}$ as described in the manufucturer's recommended procedure for the Human Foxp3 Buffer set (BD Biosciences Pharmingen). After permealization, anti-Foxp3 was added for $30 \mathrm{~min}$ at room temperature and washed once. Flow cytometry was performed on a Becton Dickinson FACSCalibur, and CellQuest Software (Becton Dickinson, Oxford, UK) was used for the analysis. The phenotype of the Tregs was defined as positive for CD4, CD25 and Foxp3.

Statistical analysis. Variables were compared by means of a non-parametric test (Mann-Whitney) for intergroup comparisons. A paired t-test was used to compare results before and after treatment. Overall survival was calculated from the first day of ACT until the last follow-up. Overall survival rates were analyzed using Kaplan-Meier curves and the related log-rank test. P-values of $<0.05$ were considered significant. All statistical analyses were performed using GraphPad Prism (version 5.0) for Windows (GraphPad Software, Inc., La Jolla, CA, USA).

\section{Results}

Patient characteristics. Patient characteristics are summarized in Table I. The median age was 63 years (range 23-89). The types of cancer varied, as shown in Table I. Only 3 patients were in a post completely resected state for their cancers, and all remaining patients had inoperable advanced or recurrent cancers. There was a number of patients with defective general status and 51 patients $(46.8 \%)$ with an Eastern Cooperative Oncology Group (ECOG) performance score of $\geq 2$. Approximately $90 \%$ of the patients had already received some treatment and most of them continued their treatment (e.g., chemotherapy, radiation therapy and hyperthermia) after starting ACT. The median frequency of ACT that patients had received was 6 times (range 0-27), and the total number of transferred LAK cells was 25 (range, 0-116.8) x $10^{9}$.

Comparison of cytokine production and absolute number, and proportion of Tregs in the peripheral blood between healthy controls and cancer patients. As shown in Table II, the level of IFN- $\alpha$ secreted $(\mathrm{P}=0.0005)$ in whole blood was significantly lower in cancer patients compared to the healthy controls, while IFN- $\gamma(\mathrm{P}=0.0007)$ secretion was significantly higher. The levels of secreted TNF- $\alpha$, IL-2, IL-4, IL-5, IL-10, IL-12(p70), IL-13 and GM-CSF in cancer patients and controls did not differ. Even though white blood cell counts in the peripheral blood did not differ between the two groups, the lymphocyte count in cancer patients was significantly lower compared to the healthy controls $(\mathrm{P}<0.0001)$. The proportion of Tregs to $\mathrm{CD}^{+}{ }^{+}$lymphocytes (Treg/CD4) did not differ between the two groups.

Effect of ACT on cytokine production. The levels of many cytokines secreted after ACT treatment were substantially altered (Table III). The value for IFN- $\alpha$ did not change after ACT treatment when compared to the value before treatment.
Table I. Clinical characteristics of the cancer patients.

Characteristics $(\mathrm{n}=109)$

Age (years)

Median (range)

Gender

Male/female

Disease site

Gastric cancer 18

Esophageal cancer

Colorectal cancer

Pancreatic cancer

Cholangioductal cancer

Hepatic cell carcinoma

Head and neck cancer

Lung cancer

Breast cancer

Uterine cancer, sarcoma

Ovarian cancer

Other

Disease status

Post-operative state

Advanced inoperable state

Recurrent

ECOG performance status

$0 / 1 / 2 / 3 / 4$

$24 / 34 / 26 / 22 / 3$

Prior treatment

None

Surgery

Chemotherapy

Radiation therapy

Other

Combined treatment

Chemotherapy

Radiation therapy

Other

Adoptive immune transfer

Frequency of transfer

$6(0-27)^{\mathrm{b}}$

Total number of transferred cells $\left(\times 10^{9}\right)$

$25(0-116.8)^{\mathrm{b}}$

${ }^{\mathrm{a}}$ One patient had both colonic and pancreatic cancer. ${ }^{\mathrm{b}}$ Median (range). ECOG, Eastern Cooperative Oncology Group.

As for Th1 cytokines, both IFN- $\gamma$ and TNF- $\alpha$ were markedly increased after ACT, while IL-12 (p70) was decreased and IL-2 did not change. As for Th2 cytokines, IL-4, IL-5, IL-13 and GM-CSF were significantly increased after ACT, while IL-10 remained unchanged. The proportions of IFN- $\gamma$ to IL-4 (IFN- $\gamma / \mathrm{IL}-4)$ and IFN- $\gamma$ to IL-10 (IFN- $\gamma / \mathrm{IL}-10)$ were both significantly increased after ACT.

Effect of ACT on the absolute number and proportion of Tregs. As shown in Table IV, the number of lymphocytes in the peripheral blood after ACT was slightly elevated compared to pre-treatment levels, but the difference was not significant 
Table II. Cytokine production and absolute number and proportion of Tregs in healthy controls and cancer patients.

\begin{tabular}{lccc}
\hline & Healthy controls $(\mathrm{n}=49)$ & Cancer patients $(\mathrm{n}=109)$ & P-value \\
\hline IFN- $\alpha$ & $6,974 \pm 3199$ & $5,102 \pm 3974$ & 0.0005 \\
IFN- $\gamma(\mathrm{pg} / \mathrm{ml})$ & $418.0 \pm 623.6$ & $1,447 \pm 2413$ & 0.0007 \\
TNF- $\alpha(\mathrm{pg} / \mathrm{ml})$ & $537.5 \pm 416.1$ & $722.7 \pm 814.0$ & $\mathrm{NS}$ \\
IL-2 $(\mathrm{pg} / \mathrm{ml})$ & $71.5 \pm 47.9$ & $123.9 \pm 146.3$ & $\mathrm{NS}$ \\
IL-4 $(\mathrm{pg} / \mathrm{ml})$ & $5.44 \pm 7.07$ & $7.11 \pm 8.71$ & $\mathrm{NS}$ \\
IL-5 $(\mathrm{pg} / \mathrm{ml})$ & $37.6 \pm 52.8$ & $69.6 \pm 122.8$ & $\mathrm{NS}$ \\
IL-10 $(\mathrm{pg} / \mathrm{ml})$ & $52.8 \pm 31.1$ & $65.7 \pm 76.2$ & $\mathrm{NS}$ \\
IL-12 $(\mathrm{p} 70)(\mathrm{pg} / \mathrm{ml})$ & $2.07 \pm 2.95$ & $6.38 \pm 31.7$ & $\mathrm{NS}$ \\
IL-13 $(\mathrm{pg} / \mathrm{ml})$ & $248.1 \pm 175.0$ & $16.77 \pm 29.98$ & $\mathrm{NS}$ \\
GM-CSF $(\mathrm{pg} / \mathrm{ml})$ & $9.58 \pm 12.62$ & $6,102 \pm 4150$ & $\mathrm{NS}$ \\
WBC $\left(/ \mathrm{mm}{ }^{3}\right)$ & $6,275 \pm 1,454$ & $1,230 \pm 572$ & $\mathrm{NS}$ \\
Lymphocyte $\left(/ \mathrm{mm}^{3}\right)$ & $2,427 \pm 690$ & $4.28 \pm 2.21$ & \\
Treg/CD4 & $4.72 \pm 1.94$ & & \\
\hline
\end{tabular}

Values are expressed as the means \pm SD. NS, not statistically significant.

Table III. Cytokine production in the cancer patients before and after ACT.

\begin{tabular}{lccc}
\hline \multirow{2}{*}{ Cytokine } & \multicolumn{2}{c}{ ACT } & P-value \\
\cline { 2 - 3 } & \multicolumn{2}{c}{ Pre } & Post \\
\hline IFN- $\alpha$ & $5,102 \pm 3,974$ & $5,941 \pm 6,584$ & NS \\
IFN- $\gamma(\mathrm{pg} / \mathrm{ml})$ & $1,447 \pm 2,413$ & $4,127 \pm 6,535$ & 0.0003 \\
TNF- $\alpha(\mathrm{pg} / \mathrm{ml})$ & $722.7 \pm 814.0$ & $1,246 \pm 1,272$ & 0.0005 \\
IL-2 $(\mathrm{pg} / \mathrm{ml})$ & $123.9 \pm 146.3$ & $163.6 \pm 304.4$ & $\mathrm{NS}$ \\
IL-4 $(\mathrm{pg} / \mathrm{ml})$ & $7.111 \pm 8.711$ & $14.70 \pm 22.04$ & 0.0001 \\
IL-5 $(\mathrm{pg} / \mathrm{ml})$ & $69.37 \pm 123.8$ & $235.1 \pm 320.1$ & $<0.0001$ \\
IL-10 $(\mathrm{pg} / \mathrm{ml})$ & $65.65 \pm 76.15$ & $69.14 \pm 73.17$ & $\mathrm{NS}$ \\
IL-12 $(\mathrm{p} 70)(\mathrm{pg} / \mathrm{ml})$ & $6.378 \pm 31.69$ & $2.855 \pm 17.38$ & 0.0400 \\
IL-13 $(\mathrm{pg} / \mathrm{ml})$ & $367.9 \pm 409.3$ & $879.4 \pm 1,230$ & $<0.0001$ \\
GM-CSF $(\mathrm{pg} / \mathrm{ml})$ & $16.77 \pm 29.98$ & $30.14 \pm 42.11$ & 0.0200 \\
IFN- $\gamma / \mathrm{IL}-4$ & $257.3 \pm 416.4$ & $388.4 \pm 694.2$ & 0.0200 \\
IFN- $\gamma / \mathrm{IL}-10$ & $26.40 \pm 39.24$ & $67.07 \pm 115.3$ & 0.0020 \\
\end{tabular}

Values are expressed as the means \pm SD. The paired t-test was used to determine statistical differences. NS, not statistically significant.

$(\mathrm{P}=0.085)$. The number and the proportion of Tregs, however, were significantly lower compared to pre-treatment values.

Relationship between immunological parameters and clinical outcome. The relationship between overall survival and immunological variables, which was altered significantly after ACT, was assessed in 76 patients whose blood samples at baseline and after four cycles of treatment were available. The median length of follow-up was 155 days (range 43-494). According to Kaplan-Meier analysis, there was a significantly longer overall survival in patients who had increased IFN- $\gamma$ secretion after ACT (log-rank test $\mathrm{P}=0.04$; Fig. 2A). Similarly, the overall survival was significantly longer in patients with increased TNF- $\alpha$ secretion after ACT (log-rank test $\mathrm{P}=0.03$; Fig. 2B). As for the Tregs, overall survival was evaluated based on the number of lymphocytes present. Thus, after ACT the overall survival tended to be longer in patients with decreased Tregs, but with normal levels of lymphocytes compared to the other patients; yet this was not statistically significant $(\log$-rank test $\mathrm{P}=0.10$; Fig. 2C).

\section{Discussion}

It remains to be determined whether ACT in patients with advanced cancer, in whom strong immunosuppression and 
Table IV. Number and proportion of Tregs in cancer patients before and after ACT.

\begin{tabular}{lccc}
\hline & \multicolumn{2}{c}{ ACT } & P-value \\
\cline { 2 - 3 } & \multicolumn{1}{c}{ Pre } & Post & \\
\hline No. of lymphocytes $\left(/ \mathrm{mm}^{3}\right)$ & $1,234 \pm 576$ & $1,333 \pm 548$ & NS \\
No. of Tregs $\left(/ \mathrm{mm}^{3}\right)$ & $20.4 \pm 14.2$ & $18.0 \pm 11.6$ & $<0.005$ \\
Treg/CD4 & $4.281 \pm 2.211$ & $3.656 \pm 2.04$ & $<0.005$ \\
\hline
\end{tabular}

Values are expressed as the means \pm SD. The paired t-test was used to determine statistical differences. NS, not statistically significant.

A

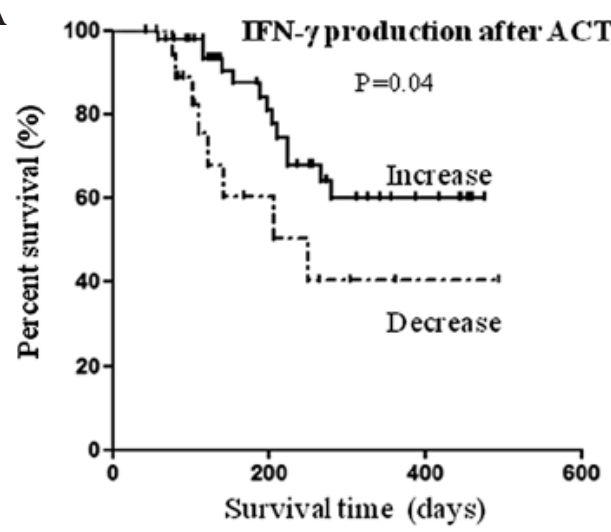

C

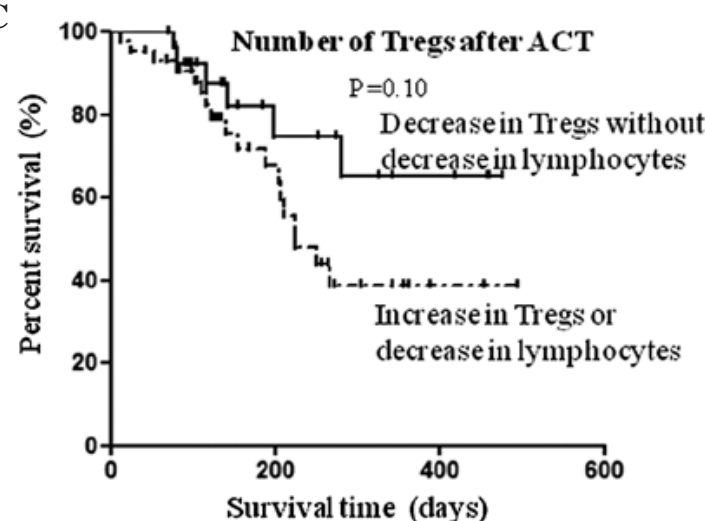

B

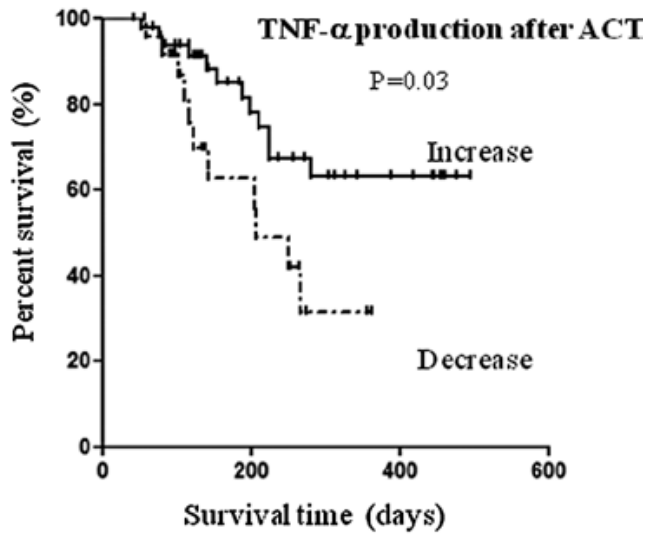

Figure 2. Kaplan-Meier survival curves of 76 patients. Association of changes in the secretion abilities of (A) IFN- $\gamma,(\mathrm{B}) \mathrm{TNF}-\alpha$ and (C) the number of Tregs after ACT treatment with overall survival in patients with advanced cancer.

immune-escape mechanisms are established, may potentially alter the undesirable immunological conditions noted in cancer. In the present study, we demonstrated that in advanced cancer patients ACT had the strong potential to enhance the Th response and to shift the balance of cytokine production to Th1. Moreover, we confirmed that ACT induced a decrease in the number of Tregs in the peripheral blood of patients with advanced cancer. In the present study, cytokine secretion and Tregs in the peripheral blood of 109 patients with various types of cancers and in 76 patients after ACT were extensively examined. To the best of our knowledge, there has been no prior clinical study reporting the effects of ACT on specific immunological parameters in patients with cancer.

When certain immunological parameters were examined in cancer patients before ACT, we found that IFN- $\alpha$ production in whole blood was significantly low compared to the healthy controls. These results agree with previous findings in patients with lung cancer and hepatocellular carcinoma $(31,32)$. Secretion of IFN- $\gamma$ in cancer patients was significantly high when compared to the healthy controls, while Th2 cytokines, such as IL-4, IL-5, IL-10 and IL-13, did not differ between the cancer patients and healthy controls. This suggests that peripheral Th cells in patients with cancer differentiate towards Th1, yet they are not active enough against cancer to result in cancer rejection. Evidence from a number of laboratories indicates that a higher amount of Tregs is observed in the blood of patients with cancer compared to healthy subjects (4-11). In disagreement with these studies, we did not find a higher amount of Tregs in patients with cancer compared to healthy subjects. This may be explained by the different conditions of the subjects between the studies. In the present study, most of the patients had previously received 
several courses of chemotherapy or radiation therapy, and their general condition had deteriorated more than that of patients in the other studies who had not received any treatment.

We demonstrated that, after four cycles of treatment, ACT enhanced the secretion of both Th1 cytokines (IFN- $\gamma$ and TNF- $\alpha$ ) and Th 2 cytokines (IL-4, IL-5, IL-13 and GM-CSF) from blood cells. ACT also had the potential to shift the balance of Th cytokines to the Th1 type in advanced cancer patients as the proportion of IFN- $\gamma$ to IL-4 was significantly increased after ACT. It is generally believed that the predominant tumoricidal effector mechanism is the cytotoxic killing effect of $\mathrm{CD}^{+} \mathrm{T}$ cells. However, increasing attention is being focused on the stimulation of $\mathrm{CD}^{+}(\mathrm{Th})$ cells in their response to cancer immunotherapy. Th cells produce many factors that are able to overcome immunosuppression and influence the tumor antigen-specific CTL response $(33,34)$. Th1 cells, characterized by their secretion of IFN- $\gamma$ and TNF- $\alpha$, are primarily responsible for activating and regulating the development and persistence of CTLs $(19,20)$. Several studies found that Th cells have direct cytolytic effects via multiple pathways involving the Fas/FasL and TNF-related apoptosisinducing ligand (TRAIL) pathways (22). In addition, Th1 cells have been found to activate antigen-presenting cells and contribute to antigen presentation to CTLs (23). Th2 cells recruit and activate eosinophils that are able to produce antitumor factors (35). Thus, Th cells mediate antitumor effects via a variety of mechanisms, by enhancing and supporting the immune environment via cytokine secretion, directly stimulating the recruitment of CTLs, directly inducing cytotoxic effects to the tumor itself and orchestrating the recruitment and activation of innate immune cells.

Romagnani et al reported that cell-mediated immunity is preferentially activated by Th1 cytokines, whereas Th 2 cytokines have a suppressive action on cell-mediated immunity (36). However, it has been clearly shown that not only Th1, but also Th2 cells initiate a CTL-based immune response in some murine tumor models. Fallarino et al showed that by infusing Th1 and Th 2 clones into tumor-bearing mice a CTL-mediated antitumor response is activated, resulting in quantitative rather than qualitative differences in antitumor activity between Th1 and Th2 cells (37). Hung et al demonstrated that protection against B16 melanoma challenge in vaccination-challenge experiments was completely eliminated in IFN- $\gamma^{-/}$mice, whereas in $\mathrm{IL}-4^{-/}$mice, protection was reduced by approximately $50 \%$ relative to vaccinated wild-type controls (35). These findings indicate that Th1 and Th2 effector mechanisms actually collaborate with each other in directing an effective antitumor response rather than antagonizing each other. These mechanisms have important implications for the development of cancer immunotherapy.

In the present study, a significant decrease in the number and proportion of Tregs in the peripheral blood was also observed. A number of studies in mice have revealed that depletion of Tregs elicits effector responses that lead to tumor eradication $(17,18)$. Therefore, manipulation of Tregs, including their depletion, blocking their trafficking into tumors or reducing their differentiation and suppressive mechanisms, represent novel strategies in cancer treatment. Previous clinical studies have demonstrated that Treg depletion alone or in combination with active immunotherapy increased effector
T cell activation (14-16). In the present study, it is suggested that ACT has a strong potential to reduce the number of Tregs. Nishikawa et al (38) showed that IFN- $\gamma$ abrogated the generation/activation of $\mathrm{CD} 4{ }^{+} \mathrm{CD} 25^{+}$Tregs. In addition, it has been shown that the amount of Tregs in tumor-bearing mice was significantly decreased by Th1 cell therapy, in which tumorspecific Th1 cells were intradermally injected with a tumor antigen near tumor-draining lymph nodes (24). The authors of that study demonstrated that the observed blockade of Treg accumulation did not occur in tumor-bearing IFN- $\gamma \mathrm{R}^{-/-}$mice. Thus, it is possible that the decrease in Tregs in the present study after ACT administration was IFN- $\gamma$-dependent as the secretion of IFN- $\gamma$ from peripheral blood cells was increased significantly after ACT. It will be necessary to examine the exact mechanism by which ACT reduces the number of Tregs in peripheral blood in more detail.

CD3-LAK cells used in this study are defined as lymphoid cells activated in vitro by exposure to IL-2 and monoclonal antibodies that bind to the CD3 complex $(26,27)$. It is generally believed that the antitumor effect of CD3-LAK cell depends on its direct lytic activity against tumors (30). Unlike CTL, which are characterized by their MHC-restricted immunoreactivity to tumor-associated antigens, CD3-LAK cells display non-specific immunoreactivity. In this study, we demonstrated that CD3-LAK therapy has a strong potential to enhance the production of both Th1 and Th2 cytokines and to reduce the number of Tregs. Furthermore, we revealed that, among the immunological parameters examined in this study, only the increase in secretion of IFN- $\gamma$ and TNF- $\alpha$ after CD3-LAK therapy correlated with survival. There were no significant differences in age, gender or performance status at the start of CD3-LAK therapy between the patients with an increase in IFN- $\gamma$ or TNF- $\alpha$ secretion and the patients without these changes (data not shown). Therefore, longer survival in the patients with increased IFN- $\gamma$ or TNF- $\alpha$ secretion can be regarded as the direct effect of CD3-LAK therapy. We provide the first evidence that CD3-LAK therapy supports the immune environment via cytokine secretion and the reduction of Tregs. Thus, it is necessary to reevaluate the potential role of CD3-LAK in cancer immunotherapy from these aspects.

In conclusion, we demonstrated that ACT has the potential to enhance the Th response and reduce the number of Tregs in advanced cancer patients who are in a strong immunosuppressive state. Overall survival is significantly longer in patients who have increased IFN- $\gamma$ or TNF- $\alpha$ secretion after receiving ACT. These findings suggest a novel potential therapeutic role of ACT in cancer immunotherapy. We believe that novel strategies of cancer immunotherapy based on these antitumor effects of ACT will succeed in the near future.

\section{Acknowledgements}

This study was partially supported by Grant-in-Aid for Young Scientists (B) from the Ministry of Education, Culture, Sports, Science and Technology of Japan (21790638).

\section{References}

1. Ribas A, Butterfield LH, Glaspy JA and Economou JS: Current developments in cancer vaccines and cellular immunotherapy. J Clin Oncol 21: 2415-2432, 2003. 
2. Rosenberg SA, Yang JC and Restifo NP: Cancer immunotherapy: moving beyond current vaccines. Nat Med 10: 909-915, 2004.

3. Liu Z, Kim JH, Falo LD II and You Z: Tumor regulatory $\mathrm{T}$ cells potently abrogate antitumor immunity. J Immunol 182 6160-6167, 2009.

4. Bluestone JA and Abbas AK: Natural versus adaptive regulatory T cells. Nat Rev Immunol 3: 253-257, 2003.

5. Ling KL, Pratap SE, Bates GJ, et al: Increased frequency of regulatory $\mathrm{T}$ cells in peripheral blood and tumour infiltrating lymphocytes in colorectal cancer patients. Cancer Immun 7: 7, 2007.

6. Wolf AM, Wolf D, Steurer M, Gastl G, Gunsilius E and Grubeck-Loebenstein B: Increase of regulatory $\mathrm{T}$ cells in the peripheral blood of cancer patients. Clin Cancer Res 9: 606-612, 2003.

7. Sasada T, Kimura M, Yoshida Y, Kanai M and Takabayashi A: $\mathrm{CD} 4{ }^{+} \mathrm{CD} 25^{+}$regulatory $\mathrm{T}$ cells in patients with gastrointestinal malignancies: possible involvement of regulatory $\mathrm{T}$ cells in disease progression. Cancer 98: 1089-1099, 2003.

8. Kono K, Kawaida H, Takahashi A, et al: CD4(+)CD25 high regulatory $\mathrm{T}$ cells increase with tumor stage in patients with gastric and esophageal cancers. Cancer Immunol Immunother 55: 1064-1071, 2006.

9. Gray CP, Arosio P and Hersey P: Association of increased levels of heavy-chain ferritin with increased $\mathrm{CD} 4^{+} \mathrm{CD} 25^{+}$regulatory T-cell levels in patients with melanoma. Clin Cancer Res 9: 2551-2559, 2003.

10. Liyanage UK, Moore TT, Joo HG, et al: Prevalence of regulatory $\mathrm{T}$ cells is increased in peripheral blood and tumor microenvironment of patients with pancreas or breast adenocarcinoma. J Immunol 169: 2756-2761, 2002.

11. Schaefer C, Kim GG, Albers A, Hoermann K, Myers EN and Whiteside TL: Characteristics of $\mathrm{CD} 4{ }^{+} \mathrm{CD} 25^{+}$regulatory $\mathrm{T}$ cells in the peripheral circulation of patients with head and neck cancer. Br J Cancer 92: 913-920, 2005.

12. Curiel TJ, Coukos G, Zou L, et al: Specific recruitment of regulatory $\mathrm{T}$ cells in ovarian carcinoma fosters immune privilege and predicts reduced survival. Nat Med 10: 942-949, 2004.

13. Nicholl M, Lodge A, Brown I, Sugg SL and Shilyansky J: Restored immune response to an MHC-II-restricted antigen in tumor-bearing hosts after elimination of regulatory $\mathrm{T}$ cells. J Pediatr Surg 39: 941-946, 2004.

14. Zou W: Regulatory $\mathrm{T}$ cells, tumour immunity and immunotherapy. Nat Rev Immunol 6: 295-307, 2006

15. Barnett B, Kryczek I, Cheng P, Zou W and Curiel TJ: Regulatory $\mathrm{T}$ cells in ovarian cancer: biology and therapeutic potential. Am J Reprod Immunol 54: 369-377, 2005.

16. Dannull J, Su Z, Rizzieri D, et al: Enhancement of vaccinemediated antitumor immunity in cancer patients after depletion of regulatory T cells. J Clin Invest 115: 3623-3633, 2005.

17. Shimizu J, Yamazaki S and Sakaguchi S: Induction of tumor immunity by removing $\mathrm{CD} 25^{+} \mathrm{CD} 4^{+} \mathrm{T}$ cells: a common basis between tumor immunity and autoimmunity. J Immunol 163: 5211-5218, 1999.

18. Onizuka S, Tawara I, Shimizu J, Sakaguchi S, Fujita T and Nakayama E: Tumor rejection by in vivo administration of anti-CD25 (interleukin-2 receptor alpha) monoclonal antibody. Cancer Res 59: 3128-3133, 1999.

19. Sun JC, Williams MA and Bevan MJ: $\mathrm{CD}^{+}{ }^{+} \mathrm{T}$ cells are required for the maintenance, not programming, of memory $\mathrm{CD} 8^{+} \mathrm{T}$ cells after acute infection. Nat Immunol 5: 927-933, 2004.
20. Pardoll DM and Topalian SL: The role of $\mathrm{CD}^{+} \mathrm{T}$ cell responses in antitumor immunity. Curr Opin Immunol 10: 588-594, 1998.

21. Schattner EJ, Mascarenhas J, Bishop J, et al: $\mathrm{CD}^{+}{ }^{+} \mathrm{T}$-cell induction of Fas-mediated apoptosis in Burkitt's lymphoma B cells. Blood 88: 1375-1382, 1996.

22. Thomas WD and Hersey P: TNF-related apoptosis-inducing ligand (TRAIL) induces apoptosis in Fas ligand-resistant melanoma cells and mediates CD4 T cell killing of target cells. J Immunol 161: 2195-2200, 1998

23. Fruh K and Yang Y: Antigen presentation by MHC class I and its regulation by interferon gamma. Curr Opin Immunol 11: 76-81, 1999.

24. Zhang Y, Wakita D, Chamoto K, et al: Th1 cell adjuvant therapy combined with tumor vaccination: a novel strategy for promoting CTL responses while avoiding the accumulation of Tregs. Int Immunol 19: 151-161, 2007.

25. Muranski P and Restifo NP: Adoptive immunotherapy of cancer using CD4(+) T cells. Curr Opin Immunol 21: 200-208, 2009.

26. Ting CC, Hargrove ME and Yun YS: Augmentation by anti-T3 antibody of the lymphokine-activated killer cell-mediated cytotoxicity. J Immunol 141: 741-748, 1988.

27. Anderson PM, Blazar BR, Bach FH and Ochoa AC: Anti-CD3 + IL-2-stimulated murine killer cells. In vitro generation and in vivo antitumor activity. J Immunol 142: 1383-1394, 1989.

28. Takayama T, Sekine T, Makuuchi M, et al: Adoptive immunotherapy to lower postsurgical recurrence rates of hepatocellular carcinoma: a randomised trial. Lancet 356: 802-807, 2000.

29. Kimura $\mathrm{H}$ and Yamaguchi Y: A phase III randomized study of interleukin-2 lymphokine-activated killer cell immunotherapy combined with chemotherapy or radiotherapy after curative or noncurative resection of primary lung carcinoma. Cancer 80: 42-49, 1997.

30. Chang AE and Shu S: Current status of adoptive immunotherapy of cancer. Crit Rev Oncol Hematol 22: 213-228, 1996.

31. Uno K, Nakano K, Maruo N, et al: Determination of interferon-alpha-producing capacity in whole blood cultures from patients with various diseases and from healthy persons. J Interferon Cytokine Res 16: 911-918, 1996.

32. Uno K, Hirosaki M, Kakimi K, et al: Impaired IFN-alpha production and the risk of cancer development. J Interferon Cytokine Res 27: 1013-1017, 2007.

33. Nishimura T, Iwakabe K, Sekimoto M, et al: Distinct role of antigen-specific T helper type 1 (Th1) and Th2 cells in tumor eradication in vivo. J Exp Med 190: 617-627, 1999.

34. Trinchieri G: Interleukin-12 and the regulation of innate resistance and adaptive immunity. Nat Rev Immunol 3: 133-146, 2003.

35. Hung K, Hayashi R, Lafond-Walker A, Lowenstein C, Pardoll D and Levitsky H: The central role of CD4(+) T cells in the antitumor immune response. J Exp Med 188: 2357-2368, 1998.

36. Romagnani S: Human TH1 and TH2 subsets: doubt no more. Immunol Today 12: 256-257, 1991.

37. Fallarino F, Grohmann U, Bianchi R, Vacca C, Fioretti MC and Puccetti P: Th1 and Th2 cell clones to a poorly immunogenic tumor antigen initiate $\mathrm{CD}^{+} \mathrm{T}$ cell-dependent tumor eradication in vivo. J Immunol 165: 5495-5501, 2000.

38. Nishikawa $\mathrm{H}$, Kato $\mathrm{T}$, Tawara I, et al: IFN-gamma controls the generation/activation of $\mathrm{CD} 4{ }^{+} \mathrm{CD} 25^{+}$regulatory $\mathrm{T}$ cells in antitumor immune response. J Immunol 175: 4433-4440, 2005. 